\title{
Rimonabant: From RIO to Ban
}

\author{
Amir H. Sam, Victoria Salem, and Mohammad A. Ghatei \\ Section of Investigative Medicine, Division of Diabetes, Endocrinology and Metabolism, Hammersmith Hospital, \\ Imperial College London, Du Cane Road, London W12 0NN, UK
}

Correspondence should be addressed to Mohammad A. Ghatei, m.ghatei@imperial.ac.uk

Received 2 February 2011; Accepted 3 May 2011

Academic Editor: Gianluca Iacobellis

Copyright (C) 2011 Amir H. Sam et al. This is an open access article distributed under the Creative Commons Attribution License, which permits unrestricted use, distribution, and reproduction in any medium, provided the original work is properly cited.

Endocannabinoid antagonism as a treatment for obesity and the metabolic syndrome became a hugely anticipated area of pharmacology at the start of the century. The CB1 receptor antagonist Rimonabant entered the European mass market on the back of several trials showing weight loss benefits alongside improvements in numerous other elements of the metabolic syndrome. However, the drug was quickly withdrawn due to the emergence of significant side effects-notably severe mood disorders. This paper provides a brief overview of the Rimonabant story and places the recent spate of FDA rejections of other centrally acting weight loss drugs entering Phase 3 trials in this context.

\section{Introduction}

The appetite regulating effects of plant-derived cannabinoids have been known for centuries. In the late 1980s and early 1990s, the discovery of specific cannabinoid G-proteincoupled receptors, $\mathrm{CB} 1$ and $\mathrm{CB} 2$, and their endogenous ligands, the endocannabinoids, opened up a major area of research into the pharmacological manipulation of this system. It culminated with the extensive clinical trialling and European marketing of Rimonabant, Sanofi-Aventis' specific CB1 receptor inverse agonist (functional antagonist) as an antiobesity agent, and ultimately its suspension due to postmarketing safety concerns. This paper provides a synopsis of this story and the lessons to be learned from it with the current generation of centrally acting weight loss drugs in late-stage clinical trials.

\section{Cannabinoid Receptor Antagonism for the Treatment of Obesity and the Metabolic Syndrome}

The endogenous cannabinoid system is widely distributed, and its physiology is not yet fully elucidated. The endocannabinoids themselves, anandamide and 2-arachidonoyl glycerol, are not stored as secretory neurotransmitters but are neuromodulators produced at the required site of action and rapidly metabolised [1]. CB2 receptors are found largely on immune cells where they modulate proinflammatory cytokine suppression [2]. More interest and development has occurred around the $\mathrm{CB} 1$ receptor, which is distributed abundantly in the central nervous system (particularly the hippocampus, basal ganglia, and hypothalamus) but has also been identified throughout the GI tract, in adipose tissue and the cardiovascular system.

The inhibition of drug-seeking behaviour by CB1 receptor antagonism [3] and observed attenuated reward behaviours in the $\mathrm{CB} 1$ receptor $\mathrm{KO}$ mouse [4] provide strong evidence for the involvement of the endocannabinoid system in motivated behaviour and hedonic responses. The induction of anxiety by cannabinoid receptor antagonism was reported a decade prior to the removal of Rimonabant from market due to adverse psychiatric effects [5]. Nevertheless, cannabinoid receptor antagonists retain an important place in the testing of animal models of addiction and conditioned behaviour and may in the future have a role in the treatment of drug dependency.

Cannabinoid modulation of hedonic responses also extends to the rewarding aspects of food consumption, which explains some of the appetite-reducing effects of Rimonabant. However, the effects of cannabinoid antagonism on appetite regulation and metabolism are far more intricate. In addition to the hedonic modulation of food 
intake in higher reward centres, the endocannabinoid system also strongly interacts with the peptidergic hypothalamic circuitry governing the homeostatic regulation of appetite and food intake [6]. Furthermore, pair-feeding studies reveal that the leaner phenotype of the $\mathrm{CB} 1$ receptor $\mathrm{KO}$ mouse is in part due to food-intake-independent mechanisms, such as elevated energy expenditure [7]. Many of these metabolic effects may be explained by actions on brain $\mathrm{CB} 1$ receptors influencing autonomic output to the gastrointestinal tract, adipose tissue, and liver. Experimentally distinguishing these centrally mediated peripheral effects from direct effects on peripherally located CB1 receptors (e.g., in adipose tissue or pancreatic islet cells) is difficult and not yet conclusive. However, there remains considerable interest in the role of peripheral $\mathrm{CB} 1$ receptors in the regulation of metabolic processes and, as a result, the potential of developing cannabinoid receptor antagonists that do not cross the blood brain barrier as a treatment for the metabolic syndrome [8]. This is due to the wider beneficial effects on glucose and lipid parameters observed in the human trials described below, apparently above and beyond those expected as a result of appetite-inhibition-driven weight loss alone.

\section{Clinical Trials Assessing Safety and Efficacy of Rimonabant}

The blockade of the CB1 receptor as a treatment for obesity has been explored in several clinical trials. In one study, obese or overweight patients $\left(\mathrm{BMI}>27 \mathrm{~kg} / \mathrm{m}^{2}\right)$ with dyslipidaemia, and/or hypertension, were randomised to double-blind treatment with placebo or Rimonabant $(5 \mathrm{mg}$ or $20 \mathrm{mg}$ once daily). All groups were also encouraged to follow a mild hypocaloric diet [9]. Rimonabant at a dose of $20 \mathrm{mg} /$ day, combined with a hypocaloric diet over 1 year, promoted a significant decrease in bodyweight and waist circumference and improvement in cardiovascular risk factors. After one year, patients treated with higherdose Rimonabant had reduced glucose and insulin levels 2 hours after oral glucose tolerance testing compared with placebo. Interestingly, this benefit continued to be seen at 2 years, when weight stabilisation had occurred. In this study Rimonabant was reported as generally well tolerated with mild and transient side effects.

The Rimonabant in Obesity-Lipids (RIO-Lipids) trial also studied the effects of Rimonabant on metabolic risk factors in high-risk patients who were overweight or obese and had dyslipidaemia [10]. The investigators randomly assigned over 1000 overweight or obese patients with untreated dyslipidaemia to double-blinded treatment with placebo or Rimonabant for 12 months in addition to a hypocaloric diet. Rimonabant at a dose of $20 \mathrm{mg}$ was associated with a significant mean weight loss, reduction in waist circumference, increase in HDL cholesterol, and reduction in triglycerides, compared with placebo. Rimonabant at a dose of $20 \mathrm{mg}$ also resulted in an increase in plasma adiponectin levels, a change that was partly independent of weight loss alone. The most frequent adverse events resulting in discontinuation of the drug were depression, anxiety, and nausea.
The RIO-North America Study Group also assessed the efficacy and safety of Rimonabant alongside lifestyle modification for sustained changes in weight and cardiometabolic risk factors over 2 years [11]. Rimonabant treatment in addition to diet promoted modest but sustained reductions in weight and waist circumference and favourable changes in cardiometabolic risk factors. This trial was limited by a high drop-out rate. The most common drug-related adverse event in this study was nausea.

The RIO-Diabetes trial assessed the efficacy and safety of Rimonabant in overweight or obese patients with type 2 diabetes inadequately controlled by metformin or sulphonylureas. Over 1000 overweight or obese type 2 diabetes patients with a haemoglobin A1c of 6.5-10.0\% already on metformin or sulphonylurea were randomly assigned to received placebo, $5 \mathrm{mg} /$ day Rimonabant, or $20 \mathrm{mg} /$ day Rimonabant for 1 year in addition to a hypocaloric diet and advice for increased physical activity [12]. Rimonabant, at a dose of $20 \mathrm{mg} /$ day, in combination with diet and exercise, produced a clinically meaningful reduction in bodyweight and improved HbAlc and a number of cardiovascular and metabolic risk factors. The incidence of adverse events that led to discontinuation was slightly greater in the $20 \mathrm{mg} /$ day Rimonabant group, mainly due to depressed mood disorders, nausea, and dizziness [12].

The SERENADE trial (The Study Evaluating Rimonabant Efficacy in Drug-Naive Diabetic Patients) assessed the glucose-lowering efficacy and safety of Rimonabant in drugnaive type 2 diabetic patients. In this 6-month, randomized double-blind placebo-controlled trial, Rimonabant resulted in improvements in glycaemic control, body weight, and lipid profile in drug-naive type 2 diabetic patients [13].

Two meta-analyses $[14,15]$ confirmed that Rimonabant treatment led to clinically meaningful weight loss, reduction in waist circumference, and improvements in several metabolic risk factors. However, findings from a meta-analysis of all published randomised controlled trials suggested that $20 \mathrm{mg}$ per day Rimonabant increases the risk of psychiatric adverse events (depressed mood disorders and anxiety) despite depressed mood being an exclusion criterion in these trials. Rimonabant caused significantly more adverse events than did placebo and 1.4 times more serious adverse events [15]. Patients given Rimonabant were 2.5 times more likely to discontinue the treatment because of depressive mood disorders than were those given placebo. Furthermore, anxiety caused more patients to discontinue treatment in Rimonabant groups than in placebo groups.

In The US Food and Drug Administration analysis of the four major trials as well as unpublished trials, psychiatric adverse events were found to be more common with Rimonabant (20 mg/day) than placebo [16]. Furthermore, two deaths from suicide were reported in patients taking Rimonabant. The drug was never approved in the United States for the treatment of obesity. The marketing approval for Rimonabant has since been removed by the European Regulatory Authorities.

\section{Lessons Learned}

Obesity-related diseases account for almost $10 \%$ of medical expenditure in the USA, or an estimated $\$ 92$ billion a year 
[17]. By 2030, the prevalence of overweight and obesity in the USA is projected to rise to $86.3 \%$ [18], forecast alongside a reversal of the 20th century gains in life expectancy due to the adverse health consequences of obesity [19]. The need and market for efficacious weight loss agents is therefore enormous. However, the history of antiobesity agents is littered with examples of drugs whose risks outweighed any potential weight loss benefits. Centrally mediated increased autonomic output has accounted for excess cardiac mortality, from the prescription of amphetamine-like drugs in the middle part of the 20th century, all the way up until the findings of the SCOUT trial which prompted the removal of Sibutramine from worldwide markets in late 2010 [20]. This followed in the wake of the refusal of the US FDA to approve the use of Rimonabant and the European Medicines Agency withdrawal of the drug, following postmarketing surveillance studies which confirmed a greater risk of depressive disorders amongst users. Both of these examples highlight the risks associated with the use of centrally acting weight loss agents, whose effects on appetite are counterbalanced by numerous other potentially hazardous effects on mood, reward, dependence, and autonomic tone. With our current incomplete understanding of the physiology governing food intake, many of these effects may be subtle or unpredictable and may only become apparent in postmarketing surveillance stage, when many more subjects are exposed to the drug. In the light of this, the FDA failed to endorse three new anti-obesity agents in 2010 because of safety concerns: Phentermine/Topiramate (Qnexa-Vivus, Inc.), Bupropion/Naltrexone (Contrave-Orexigen Therapeutics), and Lorcaserin Hydrochloride (Lorqess-Arena Pharmaceuticals). In the case of Qnexa, despite very promising late stage clinical trials demonstrating over $9 \%$ body weight loss in the treatment group [21], the FDA expressed concerns about serious potential adverse effects including suicidal ideation, cognitive issues, and tachycardia. There was also major concern over the drug's teratogenic potential, but at present Vivus are planning to resubmit application for approval to the FDA to limit its use in patients past childbearing age. In the case of Contrave, the advisory panel endorsed the drug, but the FDA decided it needed to see more cardiovascular data before it could be approved. Thus, against a background of growing suspicion and wariness, the search for efficacious, safe, and well-tolerated weight loss pharmacotherapies remains as pressing and elusive as ever.

\section{Acknowledgments}

The Section of Investigative Medicine is funded by grants from the MRC, BBSRC, NIHR, an Integrative Mammalian Biology (IMB) Capacity Building Award, an FP7-HEALTH2009-241592 EuroCHIP grant and is supported by the NIHR Imperial Biomedical Research Centre Funding Scheme. A. H. Sam is funded by a Wellcome Trust Research Training Fellowship. V. Salem is funded by an MRC Clinical Research Training Fellowship.

\section{References}

[1] J. Kim, M. Isokawa, C. Ledent, and B. E. Alger, "Activation of muscarinic acetylcholine receptors enhances the release of endogenous cannabinoids in the hippocampus," Journal of Neuroscience, vol. 22, no. 23, pp. 10182-10191, 2002.

[2] S. Munro, K. L. Thomas, and M. Abu-Shaar, "Molecular characterization of a peripheral receptor for cannabinoids," Nature, vol. 365, no. 6441, pp. 61-65, 1993.

[3] T. J. De Vries, J. R. Homberg, R. Binnekade, H. Raasø, and A. N. M. Schoffelmeer, "Cannabinoid modulation of the reinforcing and motivational properties of heroin and heroinassociated cues in rats," Psychopharmacology, vol. 168, no. 1-2, pp. 164-169, 2003.

[4] P. K. Thanos, E. S. Dimitrakakis, O. Rice, A. Gifford, and N. D. Volkow, "Ethanol self-administration and ethanol conditioned place preference are reduced in mice lacking cannabinoid CB1 receptors," Behavioural Brain Research, vol. 164, no. 2, pp. 206-213, 2005.

[5] M. Navarro, E. Hernández, R. M. Muñoz et al., "Acute administration of the $\mathrm{CB}$ cannabinoid receptor antagonist SR $141716 \mathrm{~A}$ induces anxiety-like responses in the rat," NeuroReport, vol. 8, no. 2, pp. 491-496, 1997.

[6] V. Di Marzo, S. K. Goparaju, L. Wang et al., "Leptin-regulated endocannabinoids are involved in maintaining food intake," Nature, vol. 410, no. 6830, pp. 822-825, 2001.

[7] D. Cota, G. Marsicano, M. Tschöp et al., "The endogenous cennabinoid system affects energy balance via central orexigenic drive and peripheral lipogenesis," Journal of Clinical Investigation, vol. 112, no. 3, pp. 423-431, 2003.

[8] J. Tam, V. K. Vemuri, J. Liu et al., "Peripheral CB1 cannabinoid receptor blockade improves cardiometabolic risk in mouse models of obesity," Journal of Clinical Investigation, vol. 120, no. 8, pp. 2953-2966, 2010.

[9] L. F. Van Gaal, A. M. Rissanen, A. J. Scheen, O. Ziegler, and S. Rössner, "Effects of the cannabinoid-1 receptor blocker rimonabant on weight reduction and cardiovascular risk factors in overweight patients: 1-year experience from the RIO-Europe study," Lancet, vol. 365, no. 9468, pp. 1389-1397, 2005.

[10] J. P. Després, A. Golay, and L. Sjöström, "Effects of rimonabant on metabolic risk factors in overweight patients with dyslipidemia," New England Journal of Medicine, vol. 353, no. 20, pp. 2121-2134, 2005.

[11] F. X. Pi-Sunyer, L. J. Aronne, H. M. Heshmati, J. Devin, and J. Rosenstock, "Effect of rimonabant, a cannabinoid-1 receptor blocker, on weight and cardiometabolic risk factors in overweight or obese patients-RIO-North America: a randomized controlled trial," Journal of the American Medical Association, vol. 295, no. 7, pp. 761-775, 2006.

[12] A. J. Scheen, N. Finer, P. Hollander, M. D. Jensen, and L. F. Van Gaal, "Efficacy and tolerability of rimonabant in overweight or obese patients with type 2 diabetes: a randomised controlled study," Lancet, vol. 368, no. 9548, pp. 1660-1672, 2006.

[13] J. Rosenstock, P. Hollander, S. Chevalier, and A. Iranmanesh, "SERENADE: The study evaluating rimonabant efficacy in drug-naive diabetic patients: effects of monotherapy with rimonabant, the first selective $\mathrm{CB}$ receptor antagonist, on glycemic control, body weight, and lipid profile in drug-naive type 2 diabetes," Diabetes Care, vol. 31, no. 11, pp. 2169-2176, 2008.

[14] C. Curioni and C. André, "Rimonabant for overweight or obesity," Cochrane Database of Systematic Reviews, no. 4, Article ID CD006162, 2006. 
[15] R. Christensen, P. K. Kristensen, E. M. Bartels, H. Bliddal, and A. Astrup, "Efficacy and safety of the weight-loss drug rimonabant: a meta-analysis of randomised trials," Lancet, vol. 370, no. 9600, pp. 1706-1713, 2007.

[16] http://www.fda.gov/ohrms/dockets/ac/07/briefing/2007 -4306b1-fda-backgrounder.pdf, 2011.

[17] http://www.cdc.gov/obesity/causes/economics.html, 2011.

[18] Y. Wang, M. A. Beydoun, L. Liang, B. Caballero, and S. K. Kumanyika, "Will all Americans become overweight or obese? Estimating the progression and cost of the US obesity epidemic," Obesity, vol. 16, no. 10, pp. 2323-2330, 2008.

[19] S. J. Olshansky, D. J. Passaro, R. C. Hershow et al., "A potential decline in life expectancy in the United States in the 21st century," New England Journal of Medicine, vol. 352, no. 11, pp. 1138-1145, 2005.

[20] W. P. T. James, I. D. Caterson, W. Coutinho et al., "Effect of sibutramine on cardiovascular outcomes in overweight and obese subjects," New England Journal of Medicine, vol. 363, no. 10, pp. 905-917, 2010.

[21] http://www.tesofensine-information.com/qnexa.html, 2011. 


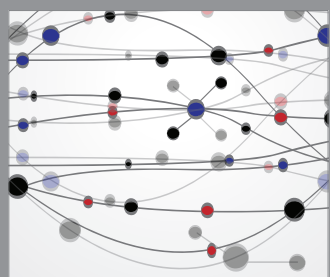

The Scientific World Journal
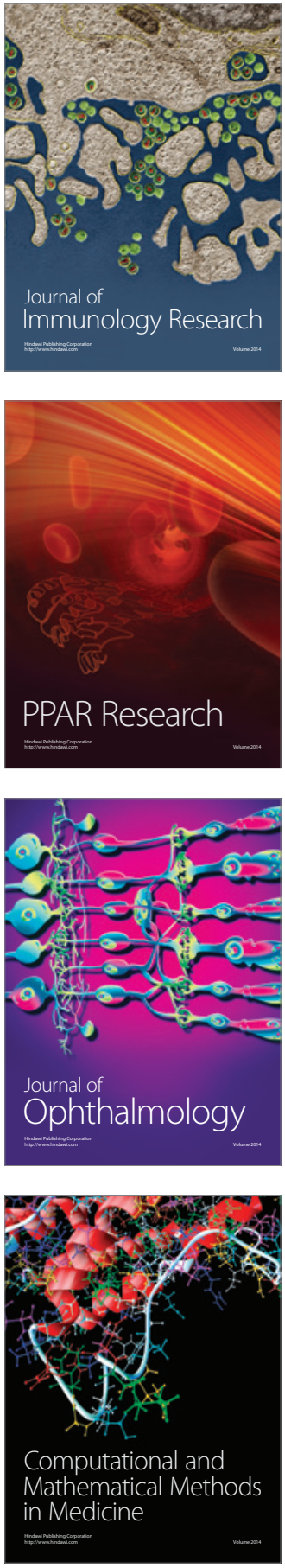

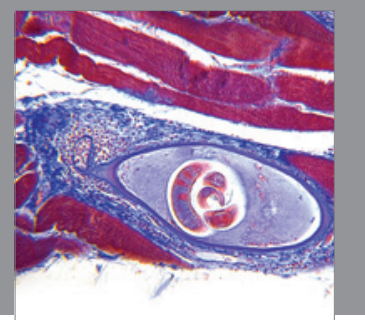

Gastroenterology

Research and Practice
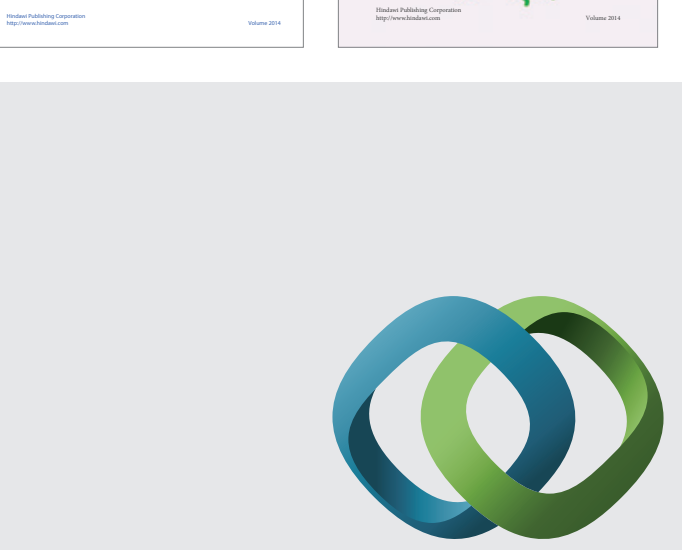

\section{Hindawi}

Submit your manuscripts at

http://www.hindawi.com
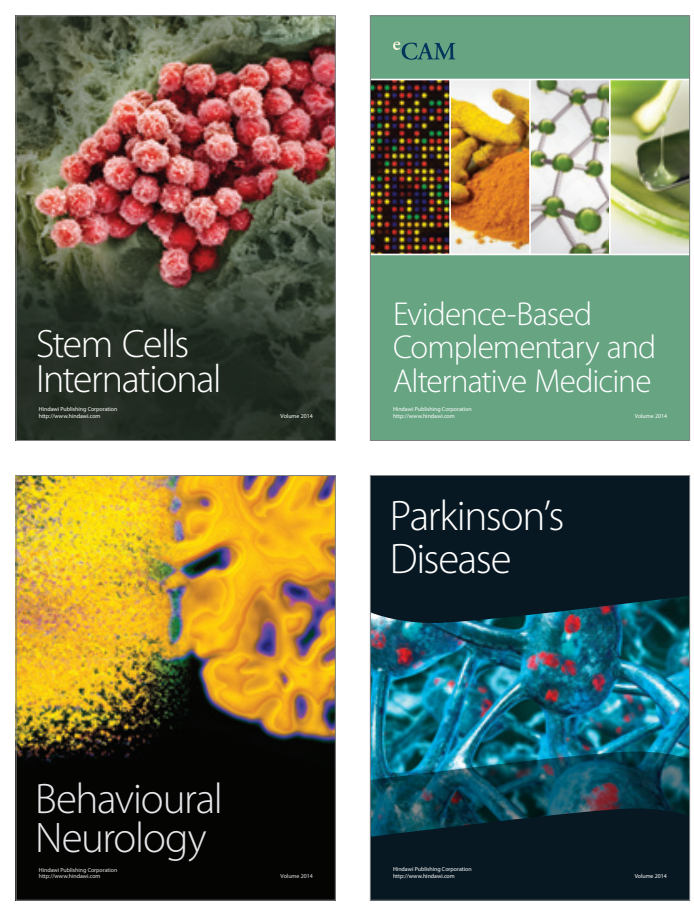

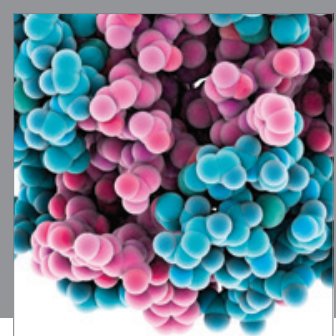

Journal of
Diabetes Research

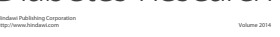

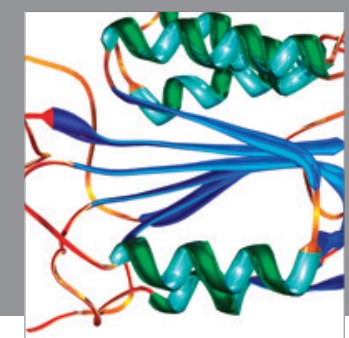

Disease Markers
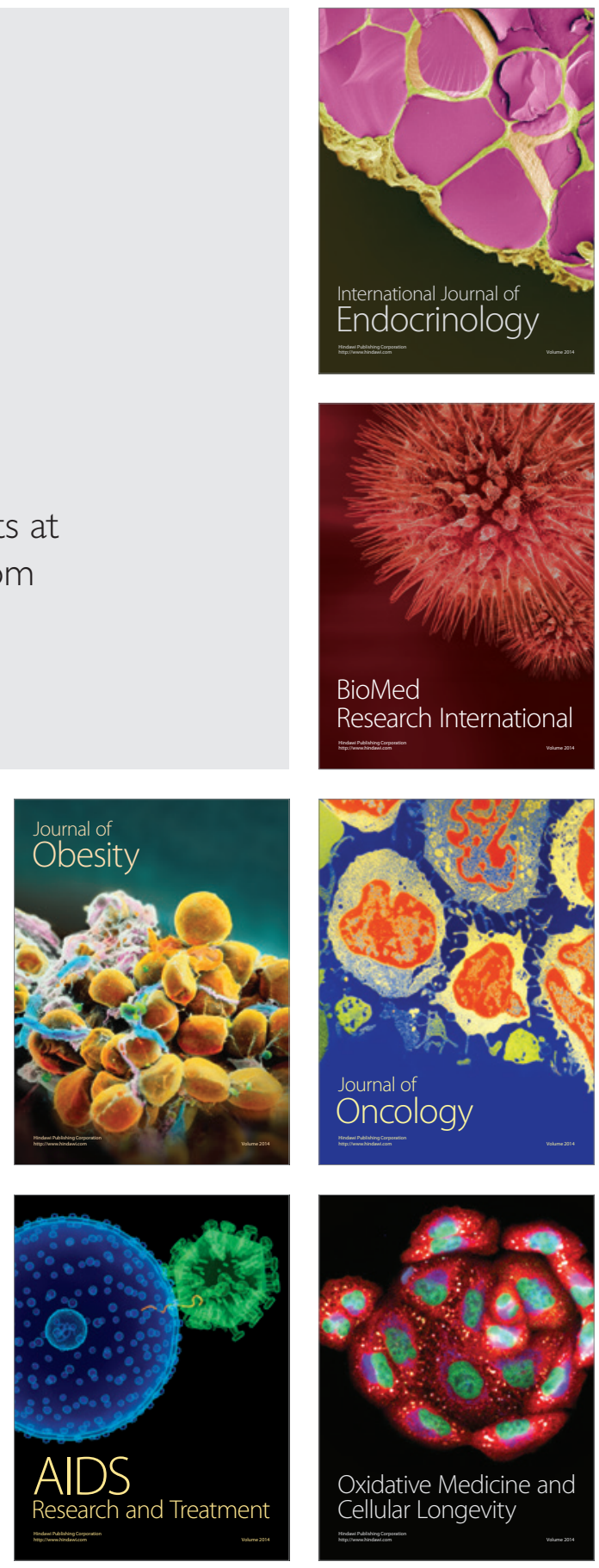